\title{
Waiting for surgery from the patient perspective
}

This article was published in the following Dove Press journal:

Psychology Research and Behavior Management

13 October 2009

Number of times this article has been viewed

Tracey Carr'

Ulrich Teucher ${ }^{2}$

Jackie Mann ${ }^{4}$

Alan G Casson ${ }^{3}$

'Health Sciences, ${ }^{2}$ Department of Psychology, ${ }^{3}$ Department of Surgery, University of Saskatchewan, Saskatoon, Saskatchewan, Canada; ${ }^{4}$ Acute Care, Saskatoon Health Region, Saskatoon, Saskatchewan, Canada
Correspondence: Tracey Carr Department of Surgery, Royal University Hospital Suite 2646, 103 Hospital Drive, Saskatoon, Saskatchewan S7N 0J6, Canada $\mathrm{Tel}+$ I 306966864 I

Fax +I 3069668026

Email tracey.carr@usask.ca
Abstract: The aim of this study was to perform a systematic review of the impact of waiting for elective surgery from the patient perspective, with a focus on maximum tolerance, quality of life, and the nature of the waiting experience. Searches were conducted using Medline, PubMed, CINAHL, EMBASE, and HealthSTAR. Twenty-seven original research articles were identified which included each of these three themes. The current literature suggested that first, patients tend to state longer wait times as unacceptable when they experienced severe symptoms or functional impairment. Second, the relationship between length of wait and health-related quality of life depended on the nature and severity of proposed surgical intervention at the time of booking. Third, the waiting experience was consistently described as stressful and anxiety provoking. While many patients expressed anger and frustration at communication within the system, the experience of waiting was not uniformly negative. Some patients experienced waiting as an opportunity to live full lives despite pain and disability. The relatively unexamined relationship between waiting, illness and patient experience of time represents an area for future research.

Keywords: wait time, scheduled surgery, patient perspective, literature review

\section{Introduction}

Wait time for health services is commonly conceptualized as a linear construct where it is assumed that patients become more distressed the longer they wait. Whether the wait for health services is a few minutes for a blood test or weeks to months for elective (scheduled) surgery, waiting can be irritating, frustrating and a source of great uncertainty. ${ }^{1}$ For patients awaiting surgery for potentially life threatening conditions such as heart disease, wait times may reveal existential concerns about fear of mortality and a degree of urgency. In addition to the nature of illness, patient characteristics and sense of time may influence the experience of waiting.

Experiences of waiting in general may be perceived as complex, subjective, and culturally influenced. ${ }^{2}$ However, the complexity of wait time is poorly understood and has been explored only to a limited extent. ${ }^{1-3}$ The connections between type of illness, waiting experience and sense of time remain relatively unexplored. Instead, most research concentrates on the maximum amount of time patients tolerate waiting and the quantitatively measured health-related quality of life (HRQOL) while waiting. This review will examine the literature related to the patient standpoint of wait time for surgery and will focus exclusively on studies that assess the patient perspective of maximum acceptable wait time and HRQOL. Specific analysis of the relationship 
between patient experience of wait time, their type of illness, and their descriptions of time ${ }^{1}$ will be emphasized.

\section{Defining wait time for surgery}

Wait times for health services in general, and for surgery in particular, have been widely publicized as a growing concern for publicly funded health care systems. Wait times may occur throughout the course of health service delivery and tend to vary depending on patient condition and supply and demand of services. Theoretically, a roster of waiting patients, or wait list, will accrue in any health care system when the overall demand for a service, such as surgery, exceeds the supply. ${ }^{4}$ However, wait lists have been acknowledged as complex phenomena influenced by patient, diagnostic, physician, hospital, government, and societal factors. ${ }^{4}$ Considerable efforts have been made to understand and improve the management of wait lists for health care services in various health care systems..$^{5-9}$

While no standardized definition exists of wait time, several wait times are acknowledged in the period leading up to procedures such as general surgery, hip and knee replacement and cataract surgery. ${ }^{10}$ These times are assessed quantitatively and counted as days or months between points in time. Generally, in the wait time literature, the period between the decision to treat and the procedure is considered the wait time. ${ }^{11}$ However, from the patient perspective total wait time, ${ }^{10}$ or the time between when a patient first experiences symptoms, seeks care and finally receives treatment, may be the most salient. Moreover, protracted wait time may have multiple meanings - waiting that is experienced as rest, as interruption, as planning, or as a completed and meaningful experience. ${ }^{2}$ How patients experience wait time may be affected by these potential meanings.

\section{Sources of wait time literature}

The wait time literature has emerged from two main sources: 1) agency and government reports and 2) academic studies. In general, the gathering of wait time data on benchmarks and best practices, complete with policy recommendations, has comprised reports from government and other agencies. ${ }^{4,7,11-14}$ This literature connects relevant clinical data to establish such benchmarks and best practices, without a specific focus on the patient perspective of the wait time experience. For example, the benchmark for scheduled cases of coronary artery bypass graft (CABG) has been determined by the Canadian Cardiovascular Society (CCS) Access to Care Working Group. ${ }^{7}$ Following a review of the literature and existing clinical practice guidelines, the Working Group surveyed cardiovascular centers and developed a consensus opinion regarding wait times. According to this consensus, the benchmark for scheduled CABG is within six weeks.?

A similar process for establishing benchmarks has occurred with scheduled hip and knee replacement surgery. The National Standards Committee of the Canadian Orthopaedic Association recommends that a patient, regardless of acuity, should not wait longer than six months for surgery. ${ }^{7}$ Moreover, the Western Canada Waiting List Project (WCWL) identified maximal acceptable wait times (MAWT) for hip and knee replacement surgery using a validated priority criteria screening tool. ${ }^{9}$ If WCWL standards are applied, the least urgent (ie, scheduled) hip and knee replacement surgery should occur within five months.

The academic literature has centered more on the development of clinically derived priority criteria systems and evaluation of those systems. ${ }^{5,11,15-29}$ General categories have been developed to broadly describe emergent, urgent, and elective (ie, scheduled) surgery or procedures. The aim of this research has been to establish standardized and reliable methods of determining fair and equitable access to health care services.

A considerable amount of the work on priority criteria systems originated in New Zealand with the development of clinical priority assessment criteria (CPAC) to book patients for scheduled procedures. ${ }^{19,20}$ When New Zealand restructured its health system in 1992, a project was designed to standardize sets of criteria to measure the presumed gains from scheduled surgical procedures. Professional advisory groups created priority standards for cataract surgery, $\mathrm{CABG}$, hip and knee replacement, cholecystectomy, and tympanostomy tubes for otitis media with effusion (chronic middle ear inflammation). Both clinical and social factors were considered when establishing priority criteria. Priority criteria were intended to help reduce surgical waiting lists and establish booking systems.

Similar to the New Zealand projects, the WCWL has derived priority criteria for several types of scheduled surgery, procedures and services. ${ }^{15,25}$ The WCWL, a federally funded partnership of 19 organizations, operates under the principle that patients with the most urgent conditions should have first priority. ${ }^{30}$ Urgency is defined as the clinical severity of the condition (ie, the extent of suffering), activity limitation, and risk of premature death. ${ }^{30}$ This definition also integrates the natural history of the condition and the expected benefits of treatment. The WCWL maintains priority and urgency may be interchangeable concepts, though priority criteria could also include social factors, such as patient lifestyle and demographics. Although the WCWL has developed criteria systems for some procedures, the extent to which these have 
been implemented as part of routine practice and studied in correlation with patient outcomes is limited.

\section{Purpose of the study}

Waiting for surgery from the patient perspective is one area of inquiry that has received relatively little emphasis in the wait list literature. The aim of the present review is to describe the research that has been conducted from the standpoint of patients awaiting scheduled surgery. Studies that investigated physical and psychological aspects of the patient experience of waiting were reviewed.

\section{Method}

\section{Search strategy}

All original articles and reviews relating to patient experiences during wait times for scheduled surgery were obtained and reviewed. Key search words were used to generate wait time information from two main databases: Medline and PubMed. Supplementary searches were conducted using CINAHL, EMBASE, and HealthSTAR. Search terms varied slightly for each database to acquire the maximum number of abstracts; the common terms were: "wait times", "waiting", "surgery", "surgical patient", "patient satisfaction", "patient experience", and "patient perspective". The search included peer- and nonpeer-reviewed literature. The searches were complete up to August 2009; the date of publication was not limited. Sources from reference lists were also collected.

\section{Inclusion and exclusion criteria}

In order to gather relevant studies regarding the patient experience of wait time for scheduled surgery, studies were originally screened using the following broad criteria: 1) English language, and 2) participants as adult patients waiting for scheduled surgery. Studies of surgery with ambiguous waits such as transplantation surgery were omitted. Cancer surgery was also not considered as surgery may be required for diagnosis and staging in addition to definitive management. Surgery can play a role at each time. Articles regarding wait times for emergency procedures were also excluded, as the focus was to understand patient experience of waiting for surgery. Furthermore, papers were not included that examined wait list cost-effectiveness or focused on rationing surgical resources or reducing wait times or wait lists, as this literature tends to measure patient demographics as opposed to patient viewpoint.

The purpose of the review was to provide a description of the literature related to the patient experience of waiting for surgery. Both qualitative and quantitative studies were considered, therefore, additional statistical analysis of the findings from each study was not performed.

\section{Results and discussion \\ Search}

MEDLINE, PubMed, CINAHL, EMBASE, HealthStar, provided $61,14,7,20$, and 48 records, respectively. When duplicate studies, letters or editorials, and articles that did not report patient experiences of waiting for surgery were discarded, 50 records remained. Further scrutiny of study abstracts reduced this number to 41 . Research studies that concentrated solely on the postoperative effects of waiting, rather than the patient experience or perception of the wait time, were also removed from the analysis. Ultimately, 27 original articles were analyzed.

\section{Study design and methods}

The majority of studies used a cross-sectional $(n=15 ; 56 \%)$ or prospective cohort design $(\mathrm{n}=9 ; 33 \%)$. The remaining three studies applied a retrospective cohort design. For most studies, wait time was defined as the length of time between the decision to treat or booking of surgery and the procedure. Data were gathered using face to face and telephone interviews, questionnaires, and surveys. The articles which examined HRQOL used physiological assessments such as the Harris Hip Score, the Western Ontario McMaster Osteoarthritis index (WOMAC), Euroqol (EQ-5D), or visual analogue scales.

The research on the patient experience of waiting for scheduled surgery generally had three objectives: to establish MAWT from the patient point of view, to assess HRQOL in relation to length of time on the wait list, and to explore the nature of the wait time experience from the patient standpoint. These three themes are presented in the following sections.

\section{Patient perspective of acceptability of wait time length}

The 11 studies investigating patient perspective of the length of wait times are presented in Table 1. The WCWL Project had several reports of patient views on the length of an acceptable wait for scheduled cataract ${ }^{31,32}$ and joint replacement ${ }^{33-35}$ surgery. What the patient perceived as the MAWT was commonly measured through the open-ended question: "In your judgment, what should be the appropriate maximum waiting time for you or a person like yourself?" MAWT has also been calculated by presenting patients with a hypothetical choice between length of wait and risk of post-operative mortality ${ }^{36}$ in order to indirectly assess 
Table I Patient perception of acceptability of wait time

\begin{tabular}{|c|c|c|c|c|c|}
\hline Study No & Surgery type & $\mathbf{N}$ & Design (Location) & Method & Main findings \\
\hline 31 & Cataract & 213 & $\begin{array}{l}\text { Cross-sectional } \\
\text { (British Columbia, } \\
\text { Canada) }\end{array}$ & $\begin{array}{l}\text { Patient perspective of MAWT, } \\
\text { VAS urgency, and visual } \\
\text { function assessment assessed } \\
\text { via mailed questionnaires }\end{array}$ & $\begin{array}{l}\text { Physician-rated MAWT was } \\
\text { significantly longer than patient-rated } \\
\text { MAWT. Sex and visual acuity in nonsurgery } \\
\text { eye significantly predicted patient MAWT }\end{array}$ \\
\hline 32 & Cataract & 166 & $\begin{array}{l}\text { Prospective cohort } \\
\text { (British Columbia, } \\
\text { Canada) }\end{array}$ & $\begin{array}{l}\text { Assessed satisfaction, MAWT, } \\
\text { urgency, visual function, visual } \\
\text { acuity, and HRQOL using } \\
\text { mailed questionnaires before } \\
\text { and 8-10 weeks after surgery }\end{array}$ & $\begin{array}{l}\text { Patients whose actual wait time was } \\
\text { shorter than MAWT had greater odds } \\
\text { of being satisfied with than those who } \\
\text { waited longer }\end{array}$ \\
\hline 33 & THA, TKA & 432 & $\begin{array}{l}\text { Cross-sectional } \\
\text { (Saskatchewan, Canada) }\end{array}$ & Questionnaire & $\begin{array}{l}\text { MAWT ratings based on pain, loss of } \\
\text { mobility, time needed to prepare, severity } \\
\text { at consultation }\end{array}$ \\
\hline 34 & THA,TKA & 233 & $\begin{array}{l}\text { Cross-sectional } \\
\text { (Alberta, Canada) }\end{array}$ & $\begin{array}{l}\text { Physician ratings of urgency, } \\
\text { MAWT; patient ratings of } \\
\text { urgency, MAWT, WOMAC }\end{array}$ & $\begin{array}{l}\text { Urgency influenced both patient } \\
\text { and surgeon MAWT. Older patients } \\
\text { reported shorter MAWT }\end{array}$ \\
\hline 35 & THA,TKA & 611 & $\begin{array}{l}\text { Cross-sectional } \\
\text { (Saskatchewan, Canada) }\end{array}$ & Questionnaire & $\begin{array}{l}63 \% \text { of patients were unlikely to change } \\
\text { surgeons to shorten wait. Male sex, high } \\
\text { school or more, and postsurgery group } \\
\text { predicted likelihood to change surgeon }\end{array}$ \\
\hline 36 & THA, TKA & 148 & $\begin{array}{l}\text { Cross-sectional } \\
\text { (Ontario, Canada) }\end{array}$ & $\begin{array}{l}\text { Measures of symptom severity } \\
\text { (WOMAC); subjective burden } \\
\text { of arthritis, choices between } \\
\text { wait time and risk to generate } \\
\text { MAWT }\end{array}$ & $\begin{array}{l}57 \% \text { chose six-month wait with } \\
\text { I\% mortality risk. MAWT ranged from } \\
\text { I-26 months, with a median of seven } \\
\text { months. Those with lower tolerance for } \\
\text { waiting reported lower utility scores and } \\
\text { shorter times since decision to treat had } \\
\text { been made }\end{array}$ \\
\hline 37 & Cataract & 550 & $\begin{array}{l}\text { Prospective cohort } \\
\text { (Manitoba, Canada; } \\
\text { Denmark; and Barcelona, } \\
\text { Spain) }\end{array}$ & $\begin{array}{l}\text { Telephone interviews identified } \\
\text { anticipated waiting time, } \\
\text { opinions about personal } \\
\text { waiting time, and visual and } \\
\text { health characteristics }\end{array}$ & $\begin{array}{l}\text { Patients in all three sites were accepting } \\
\text { of waits of three months or less, and } \\
\text { considered waits more than six months } \\
\text { to be excessive. Low tolerance for } \\
\text { waiting was associated with greater } \\
\text { self-reported difficulty with vision. } \\
\text { Acceptance of waiting was not associated } \\
\text { with clinical visual acuity measures } \\
\text { or socio-demographic characteristics }\end{array}$ \\
\hline 39 & TKA & 127 & $\begin{array}{l}\text { Retrospective cohort } \\
\text { (Ontario, Canada) }\end{array}$ & $\begin{array}{l}\text { Survey mail out with telephone } \\
\text { follow up }\end{array}$ & $\begin{array}{l}\text { Median wait times for initial consulta- } \\
\text { tion and for TKA were } 4.0 \text { and } 9.5 \\
\text { weeks, respectively. Waiting times did } \\
\text { not change significantly over the five- } \\
\text { year study period. Majority of patients } \\
\text { considered their wait time acceptable }\end{array}$ \\
\hline 40 & $\begin{array}{l}\text { THA, back } \\
\text { surgery, } \\
\text { arthroscopic } \\
\text { knee }\end{array}$ & 1336 & $\begin{array}{l}\text { Retrospective cohort } \\
\text { (Sweden) }\end{array}$ & $\begin{array}{l}\text { Questionnaire three months } \\
\text { post-operative }\end{array}$ & $\begin{array}{l}\text { Length of wait predicted patient } \\
\text { acceptance of wait time. SES variables } \\
\text { and hospital type were not related } \\
\text { to perceptions of time on wait list. } \\
\text { For arthroscopic knee surgery group } \\
\text { lack of influence over surgery date } \\
\text { was related to perception of wait time } \\
\text { as too long or unacceptable }\end{array}$ \\
\hline 41 & THA, TKA & 260 & $\begin{array}{l}\text { Cross-sectional } \\
\text { (Ontario, Canada) }\end{array}$ & $\begin{array}{l}\text { Mailed survey: length of wait, } \\
\text { acceptability of wait, effect of } \\
\text { wait on health, what acceptable } \\
\text { wait would be }\end{array}$ & $\begin{array}{l}50 \% \text { were unhappy with wait for } \\
\text { surgery or found wait unacceptable. } \\
\text { No difference between groups in } \\
\text { acceptability of wait. } 38 \% \text { rural and } 54 \% \\
\text { urban thought surgical wait contributed } \\
\text { to health deterioration }\end{array}$ \\
\hline
\end{tabular}

(Continued) 
Table I (Continued)

\begin{tabular}{llllll}
\hline Study No & Surgery type & $\mathbf{N}$ & Design (Location) & Method & Main findings \\
\hline 42 & General & 257 & $\begin{array}{l}\text { Cross-sectional } \\
\text { (Netherlands) }\end{array}$ & $\begin{array}{l}\text { Mailed survey: vignettes } \\
\text { describing physical, }\end{array}$ & Physical symptoms and impairment \\
& $\begin{array}{l}\text { surgery, } \\
\text { varicose veins, } \\
\text { inguinal hernia, }\end{array}$ & & & psychological, social and & Fork influenced MAWT judgments. \\
& gallstones & & & work impairments & to physician, surgeon and laypersons \\
& & & & \\
\hline
\end{tabular}

Abbreviations: HRQOL, health-related quality of life; MAWT, maximum acceptable wait time; VAS, visual analogue scale; THA, total hip arthroplasty; TKA, total knee arthroplasty; WOMAC, Western Ontario McMaster Osteoarthritis index; SES, socioeconomic status.

attitudes towards waiting. When patients choose a shorter wait (eg, three months versus six months) with the tradeoff of a higher risk of mortality (eg, 5\% versus 1\%), they demonstrate a greater aversion to waiting.

In a prospective cohort study, patients awaiting cataract surgery were satisfied with their wait time when their MAWT was shorter than the actual wait compared with patients who had longer waits than their MAWT. ${ }^{32}$ A comparable study measured patient and physician perspectives on MAWT for different levels of urgency according to a visual analogue scale (VAS) and visual function assessment. ${ }^{31}$ The average physician-rated MAWT was 15.1 weeks, compared to patient ratings of 9.9 weeks. From the patient perspective, MAWT for the most urgent category was four weeks. Lower MAWT was predicted by male sex and higher VAS urgency.

A multicenter international study ${ }^{37}$ of patients awaiting cataract surgery gathered pre- and post-operative interview data on socio-demographics, visual and health characteristics, anticipated wait time, and opinions about personal wait time. Length of wait was divided into "too long" versus "reasonable" or "too short". Similar to the WCWL studies, lower tolerance for waiting was positively correlated with greater self-reported visual difficulties. Patients from all centers reported accepting waits of three months or less and considered a wait time of six months or more to be too long. No relationship was found between the sociodemographics and visual acuity of the patients and their acceptance of waiting. These authors also concluded patients appear to accept wait times that are longer than those recognized as reasonable by specialists, however, subsequent studies that compared patient and physician perspectives of MAWT for cataract surgery indicate patients have lower tolerance for waiting than times identified by specialists. ${ }^{31}$

The relationship between symptom severity and MAWT for patients awaiting orthopedic surgery has been demonstrated in several studies. ${ }^{31,33,38}$ When MAWT was assessed in patients awaiting hip or knee replacement surgery, MAWT ratings were related to patient pain, loss of mobility, time needed to prepare, and severity at consultation. ${ }^{33}$ In a study of patient and surgeon perspectives on wait times for hip or knee arthroplasty, ${ }^{34}$ shorter patient MAWT was determined by greater urgency as measured by a visual analogue scale, shorter anticipated wait time, and older age. In related research, ${ }^{35}$ patients who were awaiting hip or knee arthroplasty or had undergone one of these procedures in the past year were sent a questionnaire to gauge their willingness to change surgeons to secure a shorter wait time. The majority $(63 \%)$ were unlikely to consider such a change. Those who were more likely to consider changing surgeons were male, possessed high school education or greater, and had already undergone surgery. Preference for a particular surgeon prior to referral, better HRQOL, perception of acceptable wait time to see the surgeon, and perceived fairness of treatment predicted decreased likelihood of changing surgeons for a shorter wait time.

In another study utilizing a retrospective cohort design, 39 a random sample of patients who had received knee replacement surgery during a five year period in the mid to late 1980s received a survey about their wait times. The survey collected data on the acceptability of wait time for surgical consultation and the timing of surgery. While over $80 \%$ of respondents felt their wait time for consultation and surgery were acceptable, those patients who described their wait as not acceptable waited significantly longer on average than patients who found the wait acceptable (34.3 weeks versus 13.2 weeks). Patient perception of the acceptability of the wait time was not associated with satisfaction with surgical outcomes. A similar study ${ }^{40}$ with patients who had undergone hip replacement, back surgery, or arthroscopic knee surgery measured retrospective perceptions of acceptance of wait time. Again, patients who found their wait time acceptable had considerably shorter median wait times than patients reporting their wait time as unacceptable or too long (hip replacement: 4.9 months versus 6.7 months; back surgery: 1.6 months versus 4.4 months; arthroscopic knee surgery: 1.6 months versus 2.5 months). The length of wait time 
predicted the acceptability of waiting for each of the patient groups. For patients in the back surgery group a change in the scheduled surgery date and discontent with the surgery outcome was associated with lower acceptance of wait time. Patients who had undergone arthroscopic knee surgery were more likely to report the wait time as too long when they did not have the option to influence the surgery date.

To compare actual wait times and patient perceptions of the acceptability of wait times for initial orthopedic consultation and surgery in rural versus urban areas of Ontario, Canada, a survey was sent to patients who had undergone hip or knee arthroplasty. ${ }^{41}$ Urban patients waited longer than rural patients for initial consultation; however there was no difference in wait times for surgery between the groups. The perception of the length of wait for consultation was longer than the actual wait time. For surgery, perceived length of wait corresponded to actual wait time. Approximately half of the patients ( $56 \%$ of urban and $44 \%$ of rural) were unhappy with their wait time or found the wait unacceptable. Fifty-four percent of urban patients compared to $38 \%$ of rural patients reported their wait for surgery contributed to deterioration in their health status. These reports of acceptability are considerably lower than in an earlier study, ${ }^{39}$ which could be related to overall increases in wait times.

Using the hypothetical choice assessment of conditional MAWT, the majority (57\%) of patients awaiting hip or knee replacement surgery in a cross-sectional study ${ }^{36}$ chose a six-month wait with a $1 \%$ mortality risk. Those patients with a lower tolerance for waiting reported a shorter wait time from the decision to treat than those with a higher wait time tolerance. Preferences for shorter wait times were also associated with lower subjective utility scores, a self-rating of functional status.

Former patients receiving one of three types of general surgery (varicose veins, inguinal hernia, and gallstones) offered their assessment of maximally acceptable wait times based on vignettes of patients with various levels of physical, psychological, social and work impairment. ${ }^{42}$ Severity of condition, in particular degree of physical symptoms and impairment to work, affected judgments of the MAWT. Former patient views of MAWT were similar to physician, surgeon and layperson perspectives.

\section{Patient health-related quality of life awaiting scheduled surgery}

Health-related quality of life (HRQOL) was typically assessed using quality of life instruments such as the Assessment of Quality of Life (AQOL), Euroqol (EU-5D) and Medical Outcomes Studies 36-item Short Form (SF-36) or functional status measurements such as the WOMAC and Harris Hip Scale. Six studies examined the HRQOL of patients undergoing joint replacement surgery ${ }^{38,43-47}$ and one study considered the impact of wait time on quality of life for patients undergoing coronary artery bypass surgery ${ }^{48}$ (see Table 2). HRQOL in these studies was measured at various points in patient wait time: at the decision to treat, ${ }^{43-45,47}$ at six-month ${ }^{44,47}$ and two-year ${ }^{46}$ intervals, immediately ${ }^{48}$ or two weeks ${ }^{45}$ prior to surgery, and at six weeks ${ }^{46}$ and six months $s^{46,48}$ post-operatively.

Patients placed on wait lists for hip or knee replacement surgery reported high psychological distress and poorer HRQOL than the population norm. ${ }^{43}$ This was especially the case for female patients and patients from lower socioeconomic groups. Cohort studies that followed patients on wait lists for orthopedic surgery have found the physical and HRQOL impacts of waiting are substantive. ${ }^{44,45,47}$ Longer waits correlate with physical decline, ${ }^{45}$ and shorter waits are associated with greater mobility and increased HRQOL. ${ }^{47}$ A wait time of six months or longer predicted poorer HRQOL outcomes ${ }^{44}$ for patients undergoing joint replacement surgery.

Interviews with patients waiting for hip or knee replacement surgery were conducted preoperatively and postoperatively to assess the impact of long wait times on quality of life. ${ }^{46}$ In this study, the level of pain was the main determinant of quality of life. Patients also expressed several other concerns regarding wait time quality of life including: mobility, loss of dignity, effects on family life, being alone, financial effects, and impacts on leisure activity.

One study of patients waiting for hip or knee replacement included patients undergoing prostatectomy. ${ }^{38}$ When the three patient groups were compared to national levels of HRQOL as measured by the SF-36, all patient groups scored significantly lower on every dimension. Patients awaiting hip or knee replacement had particularly low SF-36 scores on emotional and social functioning. As symptom severity increased for each patient group, quality of life decreased.

One study was found that assessed HRQOL among patients undergoing $\mathrm{CABG}^{48}$ Similar to patients waiting for orthopedic surgery, patients with heart disease awaiting surgery reported negative impacts on HRQOL as wait time increases. The impact of waiting on patients undergoing CABG was assessed using the SF-36 at decision to treat and immediately prior to surgery. ${ }^{48}$ The critical point for these patients appeared at the three-month period. For patients who waited longer than 97 days for surgery, physical 
Table 2 Patient health-related quality of life while waiting for scheduled surgery

\begin{tabular}{|c|c|c|c|c|c|}
\hline Study & Surgery type & $\mathbf{N}$ & Design (Location) & Method & Main findings \\
\hline 38 & $\begin{array}{l}\text { THA,TKA; } \\
\text { prostatectomy }\end{array}$ & $124 ; 178$ & $\begin{array}{l}\text { Cross-sectional } \\
\text { (New Zealand) }\end{array}$ & $\begin{array}{l}\text { Interviews: HRQOL, } \\
\text { condition-specific severity, } \\
\text { acceptability of wait time }\end{array}$ & $\begin{array}{l}\text { Those with more severe symptoms wanted } \\
\text { surgery sooner. Waiting represented burden re: } \\
\text { unrelieved symptoms and poor HRQOL. Other } \\
\text { issues related to wait list and health system: } \\
\text { anger, lack of understanding, difficulties planning, } \\
\text { administrative failures, reluctance to complain }\end{array}$ \\
\hline 43 & THA,TKA & 214 & $\begin{array}{l}\text { Cross-sectional } \\
\text { (Australia) }\end{array}$ & Questionnaire & $\begin{array}{l}\text { Poorer HRQOL than population norm, high } \\
\text { psychological distress; especially among women } \\
\text { and lower SES groups }\end{array}$ \\
\hline 44 & THA & 127 & $\begin{array}{l}\text { Prospective cohort } \\
\text { (Ontario, Canada) }\end{array}$ & $\begin{array}{l}\text { WOMAC at decision to treat } \\
\text { and six-month intervals }\end{array}$ & $\begin{array}{l}\text { Waiting more than six months significantly } \\
\text { increased pain and physical disability }\end{array}$ \\
\hline 45 & THA & 167 & $\begin{array}{l}\text { Retrospective } \\
\text { cohort } \\
\text { (UK) }\end{array}$ & $\begin{array}{l}\text { Physical assessment when } \\
\text { booked for surgery compared } \\
\text { to two weeks prior to } \\
\text { surgery }\end{array}$ & $\begin{array}{l}\text { Immediate preoperative Harris score decreased } \\
\text { significantly compared to initial score. Length } \\
\text { of time on the waiting list correlated with } \\
\text { decreased score }\end{array}$ \\
\hline 46 & THA,TKA & 33 & $\begin{array}{l}\text { Prospective cohort } \\
\text { (UK) }\end{array}$ & $\begin{array}{l}\text { Interviews pre and } \\
\text { post-operative }\end{array}$ & $\begin{array}{l}\text { Wait for some had been as long as five years. } \\
\text { Some sought private treatment. Quality of } \\
\text { life for all was affected by pain. Other main } \\
\text { considerations: mobility, loss of dignity, effects } \\
\text { on family life, being alone, financial effects, } \\
\text { leisure activity. Patients wanted information } \\
\text { from hospital about admission time. Improved } \\
\text { communication among partners was needed }\end{array}$ \\
\hline 47 & THA & 99 & $\begin{array}{l}\text { Prospective cohort } \\
\text { (Ontario, Canada) }\end{array}$ & $\begin{array}{l}\text { Questionnaires, baseline and } \\
\text { every six months: HRQOL, } \\
\text { WOMAC, Harris Hip Scale, } \\
\text { State-Trait Anxiety Inventory }\end{array}$ & $\begin{array}{l}\text { Longer waits relative to shorter waits were } \\
\text { not related to poorer postoperative outcomes. } \\
\text { Waits more than six months were associated } \\
\text { with decline. Shorter wait time meant greater } \\
\text { mobility and increase in HRQOL }\end{array}$ \\
\hline 48 & CABG & 266 & $\begin{array}{l}\text { Prospective cohort } \\
\text { (Quebec, Canada) }\end{array}$ & $\begin{array}{l}\text { Measures of quality of life, } \\
\text { incidence of chest pain, } \\
\text { frequency of symptoms, and } \\
\text { rates of complications }\end{array}$ & $\begin{array}{l}\text { Immediately prior to surgery, patients waiting } \\
\text { longer ( }>97 \text { days) had significantly reduced } \\
\text { physical functioning, vitality, social functioning } \\
\text { and general health. Six months after surgery, } \\
\text { longer waits were related to reduced physical } \\
\text { functioning, physical role, vitality, mental health } \\
\text { and general health. Incidence of postoperative } \\
\text { adverse events was significantly greater and } \\
\text { increased likelihood of not returning to work }\end{array}$ \\
\hline
\end{tabular}

Abbreviations: THA, total hip arthroplasty; TKA, total knee arthroplasty; HRQOL, health-related quality of life; SES, socioeconomic status; WOMAC, Western Ontario McMaster Osteoarthritis index.

functioning, vitality, social functioning and general health were significantly lower than for patients who waited 97 days or less. Longer waits were also associated with greater incidence of postoperative adverse events and decreased likelihood of return to work.

\section{Patient experience awaiting scheduled surgery}

The patient experience of waiting for scheduled surgery has been examined using qualitative ${ }^{49-54}$ and quantitative methods ${ }^{38,55}$ (see Table 3 ). Four studies explored the experience of patients awaiting various types of orthopedic surgery ${ }^{38,49,54,55}$ and five studies examined the experiences of patients undergoing coronary artery bypass surgery. ${ }^{50-53,56}$

In reviewing the research of the patient experience of waiting for joint replacement surgery, two studies ${ }^{49,54}$ used a qualitative approach to investigate the experience of "lived bodies" and "lived experience" related to wait time. The notions of "lived" body and experience come from the qualitative tradition of phenomenology, where patients encounter themselves and situations through their bodies which have intelligence to relate their personal concerns and understanding of the situation. ${ }^{49,54}$ Twelve patients scheduled for hip or knee replacement surgery were interviewed and 
Table 3 Patient experiences while waiting for scheduled surgery

\begin{tabular}{lllll}
\hline Study & Surgery type & N/Valid N & Design (Location) & Method \\
\hline 38 & THA,TKA; & $124 ; 178$ & $\begin{array}{l}\text { Cross-sectional } \\
\text { (New Zealand) }\end{array}$ & $\begin{array}{l}\text { Interviews: HRQOL, } \\
\text { condition-specific severity, } \\
\text { prostatectomy }\end{array}$ \\
& & & & acceptability of wait time
\end{tabular}

Main findings

Those with more severe symptoms wanted surgery sooner. Waiting represented burden with respect to unrelieved symptoms and poor HRQOL. Other issues related to wait list and health system were: anger, lack of understanding, difficulties planning, administrative failures, reluctance to complain

49

THA,TKA

12

50

$\mathrm{CABG}^{\mathrm{d}}$

25

51

CABG

42; 25

Cross-sectional

(Manitoba, Canada)

Qualitative longitudinal Qualitative interviews on (Sweden)

five occasions

Qualitative

cross-sectional

(Manitoba, Canada)
Qualitative telephone interviews

Preoperative themes: a deteriorating body anticipates becoming able-bodied through surgery; a frightened and mortal body

Content analysis: I) taking responsibility, 2) getting my life back, 3) getting it over with. Patients were limited by impact of symptoms, were aware of their bodies and actions exacerbating or relieving symptoms. Anxiety influenced by family, or other stories about surgery. Lengthy waits create significant psychological disturbances

Interviews suggested positive views of uncertainty-may be experienced as danger and opportunity simultaneously. No statistically significant relationship between study variables and waiting time; but a nonsignificant trend toward deterioration of psychologic and physical condition with longer waits-may have clinically significance

Prospective cohort (UK)

Prospective cohort (UK)

Cross-sectional (Sweden)
THA, TKA, shoulder, spinal, general
18

39

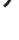

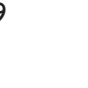

Three qualitative interviews and self-administration of State-Trait Anxiety Inventory (STAI) during waiting period

Three qualitative interviews during waiting period

Interviews one week postoperative (TKA); Interviews while waiting for THA

Questionnaires administered in face to face interview: Short-Form McGill Pain Questionnaire (MPQ), Pain Disability Index, Anxiety about Waiting and Surgery, Short Health Anxiety Inventory, Anxiety Sensitivity Index, Hospital Anxiety and Depression Scale, Coping with Health Injuries and Problems Scale
STAl scores were high at each time. Anxiety was significantly related to increased angina

Three central themes - uncertainty, chest pain, anxiety; six secondary themes - powerlessness, dissatisfaction with treatment, anger/frustration, physical incapacity, reduced self-esteem, altered family and social relationships

Paradigm case: waiting to return to a normal life. Six themes: pain restricting life activities, life on hold - continuous struggle against faceless system, living undignified, meaningless life due to pain/disability, caring needs met, living a full life - in spite of pain, disability, uncertainty, living in a supportive world

$21 \%$ were anxious, $10 \%$ were depressed, $34 \%$ had elevated health anxiety, $37 \%$ had elevated anxiety sensitivity. Concern with waiting was related to the two pain measures and health anxiety. Anxiety about surgery was related to the other two anxiety measures and MPQ. Emotional preoccupation coping was related to both pain and anxiety measures. Patient suggestions: more information on position on wait list/how wait list was managed, timeframe for surgery, more contact with those in charge; additional services: support groups, pain management, exercise programs, massage/physiotherapy, more information on condition and what to expect from procedure 
Table 3 (Continued)

\begin{tabular}{llllll}
\hline Study & Surgery type & N/Valid N & Design (Location) & Method & Main findings \\
\hline 56 & CABG & 100 & $\begin{array}{l}\text { Cross-sectional } \\
\text { (Nova Scotia, } \\
\text { Canada) }\end{array}$ & $\begin{array}{l}\text { Questionnaires, structured } \\
\text { interviews }\end{array}$ & $\begin{array}{l}84 \% \text { complained wait was stressful; 64\% noted } \\
\text { at least moderate anxiety; } 16 \% \text { expressed anger } \\
\text { over delay; only } 4 \% \text { thought queuing according } \\
\text { to medical need was unfair; } 15 \%, \text { mostly younger } \\
\text { and blue collar working patients, noted economic }\end{array}$ \\
& & & & hardship due to delayed surgery; $41 \%$ were \\
& & & & satisfied with existing institutional supports \\
\hline
\end{tabular}

Abbreviations: THA, total hip arthroplasty; TKA, total knee arthroplasty; HRQOL, health-related quality of life; CABG, coronary artery bypass graft surgery.

reported the experience of their bodies as deteriorating, frightened and mortal prior to surgery. ${ }^{49}$ Patients anticipated they would become more able-bodied through surgery. Another study of 18 patients and their lived experience while waiting for hip or knee replacement surgery ${ }^{54}$ revealed one paradigm case and six themes. The paradigm case embodied the patient reality of a life in "no man's land", where uncertainty and loss of dignity prevailed. The commonality in all cases was waiting to return to a more normal life. The first theme, pain restricting normal activities, was a common predicament for participants in this study. The second theme, a life on hold - a continuous struggle against a faceless system, was related to long wait times. Most respondents had been on the wait list for more than a year, and many had attempted, without success to find out when their surgery was scheduled. The consequences of long waits were also related to the third theme: living an undignified, meaningless life due to pain and disability. The respondents reported feelings of stigmatization, isolation, and depression. For the fourth theme, caring needs met, participants recognized the importance of established trusting relationships with care providers. In the fifth theme, some respondents reported the ability to preserve a sense of living a full life. For these respondents pain, disability, and uncertainty did not impinge on everyday life. The final theme related to having a sense of underlying support from family and friends. Support varied from assistance with practical tasks to provision of emotional encouragement. The authors ${ }^{54}$ determined respondents who had the ability to manifest meaning in their life could more easily accept wait times and wait for their turn for surgery. When the system failed to affirm the caring needs of some respondents, they experienced a struggle against a faceless enemy, "the system".

These themes ${ }^{54}$ intersect with what is understood about chronic illness and the experience of waiting. ${ }^{1}$ The interruption and uncertainty of these patients awaiting orthopedic surgery could be characterized as "lost time" and "a loss of control over time". ${ }^{1}$ Charmaz describes this time as "locked into a protracted limbo". Similarly, the paradigm case from this study embodies "no man's land"..$^{54}$

A correlational study of patients waiting for orthopedic and general surgery measured anxiety and health anxiety, depression and coping to determine which constructs would predict concern about wait time..$^{55} \mathrm{~A}$ greater proportion of patients reported concern about waiting than concern about the surgery itself. Eighty-five percent of respondents were moderately or very concerned about the waiting. Patient concern about the wait for surgery was moderately related to depression and health anxiety. Interestingly, length of wait time did not predict patient concern about waiting, which could suggest the nature rather than the duration of the wait is what is important to patients. When participants were asked what could assist them while they were waiting, two general themes emerged: support related to the wait list and provision of other services. Participants wanted information about their position on the list, a timeframe for their surgery, and more information about how the wait list was managed, including more contact with those administering the list. Other essential services reported by participants included support groups, pain management, tailored exercise programs, therapies, and further information about their condition and expectations of surgery.

In addition to measuring HRQOL and acceptable wait time, ${ }^{38}$ patients waiting for prostatectomy, hip or knee joint replacement responded to a question about the length of wait time. Participants expressed anger towards public agencies and reported difficulties planning holidays. Some participants had experienced problems with the administrative systems. There was a lack of understanding of the waiting list process, and a further lack of communication from the hospital regarding patient position on the list and possible length of wait time. At the same time, there was reluctance by some participants to complain about the length of waiting or present themselves as a 'nuisance'. 
Research describing the patient experience of waiting for $\mathrm{CABG}^{50-53}$ has gathered accounts of patient anxiety, uncertainty, and symptom distress. An additional study assessed the opinions and concerns of patients regarding wait time ${ }^{56}$ The main issue expressed by the sample of 100 patients was that the wait was stressful. Sixty-four percent disclosed moderate to severe anxiety, and $16 \%$ said they were angry due to delays. Younger patients and those still working reported economic hardships as a result of postponements. A large minority of patients (41\%) were entirely satisfied with the support received from the institution. However, $47 \%$ had complaints regarding communication about wait times. These complaints often stemmed from lack of clarity about wait time and urgency ranking. As a result, patients experienced longer than anticipated delays, a lack of awareness of whether wait time began at initial consultation or after diagnostic investigations, and unclear booking dates. Despite the availability of educational material regarding surgery, only $55 \%$ of patients received the educational package prior to their admission for surgery.

In two studies ${ }^{52,53}$ the waiting experience of 70 patients on the wait list for CABG was analyzed using a qualitative and quantitative approach. Three interviews occurred at two to four weeks, six months, and 12 months from referral for surgery. Forty-nine patients completed the second interview, and 28 were interviewed at the third interval. Data were analyzed using thematic content analysis and three central themes with six secondary and interrelated themes were identified. The three central themes were uncertainty, chest pain and anxiety. Patients felt they did not receive enough information about their wait for surgery, which meant they felt they could not plan for the future. Uncertainty was high in the initial interview, subsided at the six month interval, and peaked again when patients were followed up after one year. The second central theme, chest pain, was a major difficulty in daily lives of patients due to restricted physical activity, inhibited lifestyle and the reminder of their heart problems and the wait for surgery. These concerns about pain dissipated over time as pain management skills improved. The third central theme, anxiety, was a predominant issue; patients were anxious about their heart problem and the impending surgery. At the initial interview, patients were more concerned about their diagnosis and not surviving the wait time, while at the one-year follow up, apprehension was related to the surgery itself. When anxiety was measured quantitatively ${ }^{53}$ in the same sample of patients using the State Trait Anxiety Inventory, anxiety scores were high at all three stages of data collection.
State and trait anxiety was significantly related to increased reports of angina.

The phenomena of uncertainty, anxiety, and symptom distress have been investigated among 25 patients awaiting CABG. ${ }^{50,51}$ Content analysis of interview data noted the following categories: taking actions to manage coronary symptoms while waiting, "getting my life back" through physical and psychosocial improvements, and "getting it over with" or using cognitive and behavioral strategies to cope with impending surgery. ${ }^{50}$ Forty-two patients completed a questionnaire which measured uncertainty, anxiety, symptom frequency and related distress, and physical and social limitation. ${ }^{51}$ Actual or perceived wait time had no significant relationship to any other construct, including functional status. Symptom distress, on the other hand, was significantly associated with both anxiety and uncertainty. However, in some cases uncertainty was not perceived as a threatening experience, but rather as an opportunity once surgery was completed.

\section{Conclusions}

The literature examining the patient experience of waiting for scheduled surgery can be summarized into three categories. First, the existing research has investigated the patient perspective of MAWT. Generally, patients are less likely to report longer wait times as acceptable. This is particularly true for patients with more severe symptoms or impairment. ${ }^{31,33,36,37}$ The second focus has been to assess the relationship between length of wait and HRQOL. This relationship tends to depend on surgery type and severity at time of booking. For example, patients report wait times for joint replacement surgery of six months or longer as having a negative impact on HRQOL. ${ }^{44,47}$ Patients awaiting CABG experience significantly reduced quality of life when wait times exceed three months. ${ }^{48}$ Third, researchers have attempted to understand the nature of the waiting experience from the patient standpoint. These studies are predominately qualitative and describe the waiting experience as stressful and anxiety provoking. ${ }^{50-53,56}$ Some patients express anger and frustration about wait times ${ }^{38,52}$ and report communication issues with the system..$^{38,46,55}$ Interestingly, the experience of waiting is not uniformly negative in this research. Studies indicate some patients view the uncertainty during waiting as an opportunity to consider surgery as a second chance ${ }^{51}$ and are able to live full lives despite pain and disability. ${ }^{54}$

The studies of the nature of the patient experience awaiting joint replacement and CABG illustrate some common concerns among participants. Both patient groups tend to 
cite a measure of uncertainty in the waiting period prior to surgery. This theme is especially prevalent among patients awaiting CABG where existential concerns about mortality risk are emphasized. While each patient group reports positive aspects to the waiting experience, a recurring theme in most studies was lack of information and communication during the wait period. In one study, the "system" was viewed as a faceless "enemy". 54

\section{Limitations}

The limitations of this review are influenced by the characteristics of the original references. Some studies using a cross-sectional or retrospective cohort design asked patients who were no longer on the waiting list for their MAWT opinions, their perceptions of HRQOL, and/or their wait time experiences. It is likely patient perspectives of waiting are influenced by the specific time in the waiting process. Asking patients postoperatively about their wait time may reveal substantially different perceptions. For example, when two groups of patients before and after joint replacement surgery were surveyed, being in the postoperative surgery group predicted the likelihood to change surgeons to achieve a shorter wait time. ${ }^{35}$

Although this review provides a description of the current state of the literature on the patient perspective of waiting for scheduled surgery, several questions remain. Opportunities exist to further explore patient conceptions of time, waiting, and coping with the preoperative period. Given the multiple experiences of wait time as a fount of opportunity and meaning or as a source of uncertainty and despair, additional studies of patient perspectives on waiting could examine conceptions of "life on hold" versus "waiting as opportunity". Such investigations could invoke systematic change to support patients during the waiting period.

Only three studies ${ }^{46,52,54}$ made specific clinical and/or policy recommendations based on their findings. Given the significance of wait times for patients, service providers, and the health system, translating research findings into practical solutions to assist patients during their wait period is essential. Until the waiting experience of patients is more fully understood, evaluation research on interventions designed to improve the patient experience will be limited.

\section{Future directions}

Further investigation into the conditions that influence patient experience of waiting for scheduled surgery is required. Because the experience of wait time is complex, the past, present and future will have an impact on patient self-perceptions. ${ }^{1,57}$ Very few studies have examined the complexity and subjectivity of wait time. The connections between illness type, wait experience, patient characteristics and sense of time should be explored. Greater understanding of patient experience will enhance support for those waiting for scheduled surgery.

\section{Acknowledgments}

This research is supported by the Canadian Institutes of Health Research, Frederick Banting and Charles Best Canada Graduate Scholarships - Doctoral Award. The authors report no conflicts of interest in this work.

\section{References}

1. Charmaz K. Good days, bad days: the self in chronic illness and time. New Brunswick, NJ: Rutgers University Press; 1991.

2. Gasparini G. On waiting. Time and Society. 1995;4(1):29-42.

3. Gross E. Waiting at Mayo. Urban Life. 1986;15(2):139-164.

4. McDonald P, Shortt S, Sanmartin C, Barer ML, Lewis S, Sheps S. Waiting lists and waiting times for health care in Canada: more management!! More money?? Summary Report. July, 1998. Available from: http://www.chspr.ubc.ca/files/publications/1998/hpru98-09D-A. pdf. Accessed February 16, 2009.

5. McGurran J, Noseworthy T. Steering Committee of the Western Canada Waiting List, Project. Improving the management of waiting lists for elective healthcare services: public perspectives on proposed solutions. Hosp Q. 2002;5(3):28-32.

6. Pitt DF. Waiting lists: management, legalities and ethics. Can J Surg. 2003;46(3):170.

7. Canadian Medical Association; Wait Time Alliance. It's about time! Achieving benchmarks and best practices in wait time management. August 2005. Available from: http://www.cma.ca/multimedia/CMA/ Content_Images/Inside_cma/Media_Release/pdf/2005/wta-final.pdf. Accessed February 16, 2009.

8. Canadian Medical Association; Wait Time Alliance. Time for progress: New benchmarks for achieving meaningful reductions in wait times. November 2007. Available from: http://www.waittimealliance.ca/ images/Fall_2007/ time_for_progress.pdf. Accessed February 16, 2009

9. Western Canada Waiting List Project. Moving forward: final report. February 28, 2005. Available from: http://www.wcwl.org/media/pdf/ news/moving_forward/report.pdf. Accessed February 18, 2009.

10. Sanmartin C. Steering Committee of the Western Canada Waiting List Project. Toward standard definitions for waiting times. Healthc Manage Forum. 2003:49-53.

11. Masri BA, Cochrane N, Dunbar M, Duncan C, Hughes K, Kopec J, et al. Priority criteria for hip and knee replacement: addressing health service wait times. Report 1 Literature Review: Waiting, Consequences and Benchmarks for Joint Replacement. July 2005. Available from: http://www.plexia. ca/masri/Waiting\%20Report\%20I\%20July\%2021_Final_.pdf. Accessed February 20, 2009.

12. Glynn P, Taylor M, Hudson A. Surgical wait list management: a strategy for Saskatchewan. January, 2002. Available from: http:// www.health.gov.sk.ca/surgical-wait-list-management. Accessed February 20, 2009.

13. Canadian Institute for Health Information. Waiting for health care in Canada: what we know and what we don't know. 2006. Available from: http://secure.cihi.ca/cihiweb/dispPage.jsp? cw_page=AR_1385_E. Accessed February 20, 2009.

14. Canadian Medical Association. The economic cost of wait times in Canada. January 15, 2008. Available from: http://www.ooa. ca/files/economic $\% 20$ costs $\% 20$ of $\% 20$ wait $\% 20$ time.pdf. Accessed February 20, 2009. 
15. Arnett G, Hadorn DC. Steering Committee of the Western Canada Waiting List Project. Developing priority criteria for hip and knee replacement: results from the Western Canada Waiting List Project. Can J Surg. 2003;46(4):290-296.

16. Conner-Spady B, Estey A, Arnett G, et al. Prioritization of patients on waiting lists for hip and knee replacement: validation of a priority criteria tool. Int J Technol Assess Health Care. 2004;20(4):509-515.

17. Conner-Spady BL, Arnett G, McGurran JJ, Noseworthy TW, Steering Committee of the Western Canada Waiting List Project. Prioritization of patients on scheduled waiting lists: validation of a scoring system for hip and knee arthroplasty. Can J Surg. 2004;47(1):39-46.

18. Derrett S, Devlin N, Hansen P, Herbison P. Prioritizing patients for elective surgery: a prospective study of clinical priority assessment criteria in New Zealand. Int J Technol Assess Health Care. 2003; 19(1):91-105.

19. Hadorn DC, Holmes AC. The New Zealand priority criteria project. Part 1: Overview. BMJ. 1997;314(7074):131-134.

20. Hadorn DC, Holmes AC. The New Zealand priority criteria project. Part 2: Coronary artery bypass graft surgery. BMJ. 1997;314(7074): $135-138$.

21. Hadorn DC. Steering Committee of the Western Canada Waiting List Project. Developing priority criteria for magnetic resonance imaging: results from the Western Canada Waiting List Project. Can Assoc Radiol J. 2002;53(4):210-218.

22. MacCormick AD, Collecutt WG, Parry BR. Prioritizing patients for elective surgery: a systematic review. ANZ J Surg. 2003;73(8): 633-642.

23. Martin DK. Priority setting in surgery: improve the process and share the learning. World J Surg. 2003;27(8):962-966.

24. Naylor CD, Szalai JP, Katic M. Benchmarking the vital risk of waiting for coronary artery bypass surgery in Ontario. CMAJ. 2000;162(6): 775-779.

25. Noseworthy TW, McGurran JJ, Hadorn DC. Steering Committee of the Western Canada Waiting List Project. Waiting for scheduled services in Canada: development of priority-setting scoring systems. J Eval Clin Pract. 2003;9(1):23-31.

26. Ray AA, Buth KJ, Sullivan JA, Johnstone DE, Hirsch GM. Waiting for cardiac surgery: results of a risk-stratified queuing process. Circulation 2001;104(12 Suppl 1):92-98.

27. Romanchuk KG, Sanmugasunderam S, Hadorn DC. Steering Committee of the Western Canada Waiting List Project. Developing cataract surgery priority criteria: results from the Western Canada Waiting List Project. Can J Ophthalmol. 2002;37(3):145-154.

28. Taylor MC, Hadorn DC, Steering Committee of the Western Canada Waiting List Project. Developing priority criteria for general surgery: results from the Western Canada Waiting List Project. Can J Surg. 2002;45(5):351-357.

29. Wright D, Arthur H. An analysis of the impact of a management system on patients waiting for cardiac surgery. Can J Cardiovasc Nurs. 1996;7(1):5-9.

30. Hadorn DC. Setting priorities for waiting lists: defining our terms. Steering Committee of the Western Canada Waiting List Project. CMAJ. 2000;163(7):857-860.

31. Conner-Spady BL, Sanmugasunderam S, Courtright P, et al. Patient and physician perspectives of maximum acceptable waiting times for cataract surgery. Can J Ophthalmol. 2005;40(4):439-447.

32. Conner-Spady BL, Sanmugasunderam S, Courtright P, McGurran JJ, Noseworthy TW. Steering Committee of the Western Canada Waiting List Project. Determinants of patient satisfaction with cataract surgery and length of time on the waiting list. Br J Ophthalmol. 2004; 88(10):1305-1309.

33. Conner-Spady BL, Johnston GH, Sanmartin C, McGurran JJ, Noseworthy TW. Saskatchewan Surgical Care Network/Western Canada Waiting List Project Research and Evaluation Working Group Committee. A bird can't fly on one wing: patient views on waiting for hip and knee replacement surgery. Health Expect. 2007;10(2): $108-116$.
34. Conner-Spady B, Estey A, Arnett G, et al. Determinants of patient and surgeon perspectives on maximum acceptable waiting times for hip and knee arthroplasty. J Health Serv Res Policy. 2005;10(2):84-90.

35. Conner-Spady B, Sanmartin C, Johnston G, McGurran J, Kehler M, Noseworthy T. Willingness of patients to change surgeons for a shorter waiting time for joint arthroplasty. CMAJ. 2008;179(4): 327-332.

36. Llewellyn-Thomas HA, Arshinoff R, Bell M, Williams JI, Naylor CD. In the queue for total joint replacement: patients' perspectives on waiting times. Ontario Hip and Knee Replacement Project Team. J Eval Clin Pract. 1998;4(1):63-74.

37. Dunn E, Black C, Alonso J, Norregaard JC, Anderson GF. Patients' acceptance of waiting for cataract surgery: what makes a wait too long? Soc Sci Med. 1997;44(11):1603-1610.

38. Derrett S, Paul C, Morris JM. Waiting for elective surgery: effects on health-related quality of life. Int J Qual Health Care. 1999;11(1): 47-57.

39. Ho E, Coyte PC, Bombardier C, Hawker G, Wright JG. Ontario patients' acceptance of waiting times for knee replacements. J Rheumatol. 1994;21(11):2101-2105.

40. Lofvendahl S, Eckerlund I, Hansagi H, Malmqvist B, Resch S, Hanning M. Waiting for orthopaedic surgery: factors associated with waiting times and patients' opinion. Int J Qual Health Care. 2005;17(2): 133-140.

41. Snider MG, MacDonald SJ, Pototschnik R. Waiting times and patient perspectives for total hip and knee arthroplasty in rural and urban Ontario. Can J Surg. 2005;48(5):355-360.

42. Oudhoff JP, Timmermans DR, Rietberg M, Knol DL, van der Wal G. The acceptability of waiting times for elective general surgery and the appropriateness of prioritising patients. BMC Health Serv Res. 2007;7:32.

43. Ackerman IN, Graves SE, Wicks IP, Bennell KL, Osborne RH. Severely compromised quality of life in women and those of lower socioeconomic status waiting for joint replacement surgery. Arthritis Rheum. 2005;53(5):653-658.

44. Davis AM, Agnidis Z, Badley E, et al. Waiting for hip revision surgery: the impact on patient disability. Can J Surg. 2008;51(2):92-96.

45. Kili S, Wright I, Jones RS. Change in Harris hip score in patients on the waiting list for total hip replacement. Ann R Coll Surg Engl. 2003;85(4):269-271.

46. Rigge M. Quality of life of long wait orthopaedic patients before and after admission: a consumer audit. Qual Health Care. 1994;3(3): 159-163.

47. Mahon JL, Bourne RB, Rorabeck CH, Feeny DH, Stitt L, WebsterBogaert S. Health-related quality of life and mobility of patients awaiting elective total hip arthroplasty: a prospective study. CMAJ. 2002;167(10): 1115-1121.

48. Sampalis J, Boukas S, Liberman M, Reid T, Dupuis G. Impact of waiting time on the quality of life of patients awaiting coronary artery bypass grafting. CMAJ. 2001;165(4):429-433.

49. Gustafsson BA, Ponzer S, Heikkilä K, Ekman SL. The lived body and the perioperative period in replacement surgery: older people's experiences. J Adv Nurs. 2007;60(1):20-28.

50. McCormick KM, McClement S, Naimark BJ. A qualitative analysis of the experience of uncertainty while awaiting coronary artery bypass surgery. Can J Cardiovasc Nurs. 2005;15(1):10-22.

51. McCormick KM, Naimark BJ, Tate RB. Uncertainty, symptom distress, anxiety, and functional status in patients awaiting coronary artery bypass surgery. Heart Lung. 2006;35(1):34-45.

52. Fitzsimons D, Parahoo K, Stringer M. Waiting for coronary artery bypass surgery: a qualitative analysis. JAdv Nurs. 2000;32(5):1243-1252.

53. Fitzsimons D, Parahoo K, Richardson SG, Stringer M. Patient anxiety while on a waiting list for coronary artery bypass surgery: a qualitative and quantitative analysis. Heart Lung. 2003;32(1):23-31.

54. Sjoling RN, Agren RN, Olofsson N, Hellzen RN, Asplund RN. Waiting for surgery; living a life on hold - a continuous struggle against a faceless system. Int J Nurs Stud. 2005;42(5):539-547. 
55. Janzen JA, Hadjistavropoulos HD. Examination of negative affective responses to waiting for surgery. Can J Nurs Res. 2008;40(4):72-91.

56. Petrie JF, Cox JL, Teskey RJ, Campbell LB, Johnstone DE. Preliminary assessment of patients' opinions of queuing for coronary bypass graft surgery at one Canadian centre. Qual Health Care. 1996;5(3): $166-171$
57. Adam B. Perceptions of time. In: Ingold T (editor). Companion encyclopedia of anthropology. London, UK: Routledge; 1997. p. 503-526.

Psychology Research and Behavior Management

\section{Publish your work in this journal}

Psychology Research and Behavior Management is an international, peerreviewed, open access journal focusing on the science of psychology and its application in behavior management to develop improved outcomes in the clinical, educational, sports and business arenas. Specific topics covered include: Neuroscience, memory \& decision making; Behavior modification \& management; Clinical applications; Business \& sports performance management; Social and developmental studies; Animal studies. The manuscript management system is completely online and includes a quick and fair peer-review system. Visit http://www.dovepress. com/testimonials.php to read real quotes from published authors.

Submit your manuscript here: http://www.dovepress.com/psychology-research-and-behavior-management-journal 